\title{
Plasma Characterization of Pulsed-Laser Ablation Process Used for Fullerene-like CNx Thin Film Deposition
}

\author{
H. Riascos ${ }^{1,2}$, G. Zambrano ${ }^{2}$, and P. Prieto ${ }^{2}$ \\ ${ }^{1}$ Departamento de Física, Universidad Tecnológica de Pereira, Pereira, Colombia \\ ${ }^{2}$ Departamento de Física, Universidad del Valle, Cali, Colombia
}

Received on 14 January, 2004; revised version received on 21 April, 2004

\begin{abstract}
An in situ Optical Emission Spectroscopy (OES) characterization was performed on Pulsed-Laser Ablation (PLA) process used for fullerene-like $\mathrm{CNx}$ thin film deposition at nitrogen pressures within the $5-100 \mathrm{mTorr}$ range. Plumes were generated by ablation of pyrolytic graphite $(99.99 \%)$ target using a (500 mJ, $7 \mathrm{~ns}, 1064$ nm) Nd: YAG-pulsed laser. The spectra from the plume show, essentially, the presence of the band heads of $\mathrm{CN}$ Violet vibrational/rotational $\mathrm{B}^{2} \Sigma^{+}-\mathrm{X}^{2} \Sigma^{+}$system and the characteristic $\mathrm{C}_{2}$ emission lines, belonging to the Swan $\mathrm{A}^{3} \Pi_{g}-\mathrm{X}^{3} \Pi_{u}$ system. These excited $\mathrm{CN}$ and $\mathrm{C}_{2}$ molecules were generated by laser ablation and by collisions of the plume with the substrate surface. Their vibrational temperatures were strongly dependent on nitrogen pressure during the deposition process and presented a decrease between 2.64 and $1.23 \mathrm{eV}$, as pressure increased from 5 to 100 mTorr. Synthesis of fullerene-like structures required high molecular temperatures at the condensation surface. High concentrations of $\mathrm{CN}$ radicals in the plasma promoted nitrogen incorporation into the films. The OES plasma characterization allowed for a correlation of the concentration and vibrational temperatures of $\mathrm{CN}$ and $\mathrm{C}_{2}$ species present in the plasma with the fullerene-like $\mathrm{CN}_{x}$ film composition and bonding, determined by XPS, IR, and Raman spectroscopy.
\end{abstract}

\section{Introduction}

Pulsed Laser Deposition (PLD) technique has attracted much attention in recent years for the synthesis of thin films of different materials, such as: high temperature superconductors, ferroelectrics, nitride and metal compounds, and fullerene carbon molecules. On the other hand, because the average energy of laser-ablated species is much higher than kT and a certain fraction of these species is ionized, it is possible to form metastable phases such as diamondlike carbon (DLC) and fullerene-like amorphous carbon nitride, $\mathrm{CNx}$, materials from a graphite target in nitrogen atmospheres [1,3]. For this reason, laser-ablated carbon plumes have been widely characterized. Since the dynamic behaviour of species in the laser-ablated plasma plume affects the characteristic of deposited thin films, many publications aim to understand the PLD process and the correlation between composition, structure, and properties of deposited films, plasma parameters, and chemical state of species present in the plasma [1-3]. Different techniques such as Optical Emission Spectroscopy (OES) [1,3,4], time-offlight mass spectroscopy $[1,3,5]$, laser-induced fluorescence spectroscopy [6], interferometry [7], and Langmuir probe method [8] have been used in order to understand and control the deposition process. Among the various diagnostic techniques, which are convenient tools in the detection of different chemical species, the OES has remarkable advantages appertaining to high spatial and temporal resolution for in situ characterization without perturbation of the plasma. From the intensities and contour forms of the observed emis- sion spectra in the OES, useful plasma parameters such as: electron temperature and density [9], kinetic energy of ablated species, and vibrational temperature of molecules can be estimated [1-4]. This work analyzes plasma chemistry, physics, and vibrational temperature of $\mathrm{CN}$ and $\mathrm{C}_{2}$ species present in the plume close to the target surface. Results permit a possible optimization of plasma ionization and molecular excitation for fullerene-like $\mathrm{CN}_{x}$ thin film deposition at different nitrogen pressures.

\section{Experimental details}

The experimental set up is shown in Fig. 1. CNx films were deposited by pulsed-laser ablation of high purity $(99.99 \%)$ pyrolytic graphite target in a nitrogen atmosphere using an INDI-30 Spectra-Physic Q-switched Nd YAG-pulsed laser (energy $500 \mathrm{~mJ}$, wavelength $1064 \mathrm{~nm}$, and pulsed width 7 ns) operated at $10 \mathrm{~Hz}$. Laser-ablated carbon fragments were deposited onto silicon substrates and combined with active nitrogen species present in the plasma. Films were deposited at a substrate temperature near $300{ }^{0} \mathrm{C}$. The target was placed $25 \mathrm{~mm}$ from the substrate and oriented $45^{0}$ with respect to the substrate. The vacuum chamber was evacuated down to an approximate pressure of $2 \times 10^{-4}$ mTorr, before each deposition. Nitrogen gas pressure was varied in the 5100 mTorr range. The angle of laser incidence on the target was $45^{\circ}$ and focused onto such by means of a glass lens to give fluency around $10-12 \mathrm{~J} / \mathrm{cm}^{2}$. Under these conditions, the growth rate was $10-12 \mathrm{~nm} / \mathrm{min}$. 


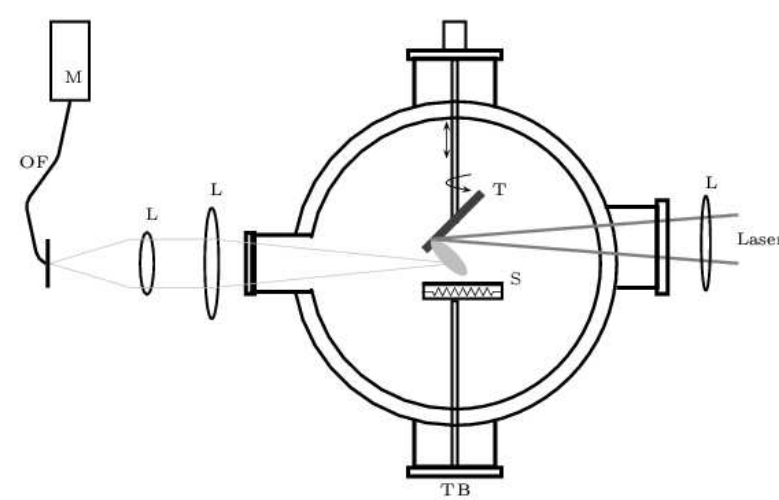

Figure 1. Experimental Setup: M-monochromator, OF-optical fiber, L-focusing lens T-target, S-substrate, TB-turbomolecular pump.

Plasma chemistry was determined by spectroscopy analysis of the emitted light. Optical emission from the ablation plasma plume, generated by the Nd YAG laser irradiation of the carbon target in nitrogen, was collected by a bundled optical fiber (diameter $2 \mathrm{~mm}$ ) placed outside the quartz window, approximately $20 \mathrm{~cm}$ from the target surface, and fixed in such manner as to permit detection of the maximum light emission. The 4:1 ratio corresponding to the observed area of the plasma plume and images, gives a spatial resolution of $4 \mathrm{~mm}$ in diameter. The other end of the fiber is coupled to the entrance slit of a $0.55 \mathrm{~m}$ spectrograph (Triax 550, Jobin Yvon-Spex, f/6.4) equipped with a CCD camera for multi-channel detection and a $1200 \mathrm{l} / \mathrm{mm}$ grid with spectral resolution of $0.025 \mathrm{~nm}$. The grid was moved in $20 \mathrm{~nm}$ sequences and the collected spectra were "assembled" to obtain a spectra in the $300-700 \mathrm{~nm}$ range.

\section{Results and discussion}

Characteristic emission spectra collected over 350-650 nm during the laser ablation of graphite at $12 \mathrm{~J} / \mathrm{cm}^{2}$ and 30 mTorr of nitrogen background pressure is illustrated in Fig. 2. The emission sampling point was nearly $1 \mathrm{~cm}$ away from the target and spectra collection time was $1 \mathrm{~s}$, providing integration over several complete laser ablation events at the laser repetition rate of $10 \mathrm{~Hz}$. In Fig. 2 we observe that emission spectra at $30 \mathrm{mTorr}$ is dominated by very strong peaks of excited neutral, C(I), and single ionized, C(II), atoms. Additionally, we evidence much weaker $\mathrm{CN}$ emission lines of band heads from the Violet vibration/rotational $\mathrm{B}^{2} \Sigma^{+}$$\mathrm{X}^{2} \Sigma^{+}$system, characteristic for carbon plasma in the presence of reactive nitrogen $[1-4,10]$. The most dominant $\mathrm{CN}$ sequences had head positions at 385-391 and 415-422 nm. Another result was the detection of $\mathrm{C}_{2}$ molecular species in the nitrogen atmosphere, evidenced from characteristic emission lines belonging to the Swan $\mathrm{A}^{3} \Pi_{g}-\mathrm{X}^{3} \Pi_{u}$ system. Detection of $\mathrm{C}_{2}$ molecules is related to plume thermalization caused by collisions with background nitrogen molecules, promoting recombination of $\mathrm{C}$ to form $\mathrm{C}_{2}$ [11]. Fullerenelike CNx films have predominantly graphite-like structures and require $\mathrm{sp}^{2}$ electron hybridization. Plume thermalization and a greater availability of $\mathrm{C}_{2}$ species provide a large fraction of $\mathrm{sp}^{2}$ hybridization as opposed to $\mathrm{sp}^{3}$ hybridization, also observed in high-quality DLC films produced from laser plumes in PLD processes.[2].

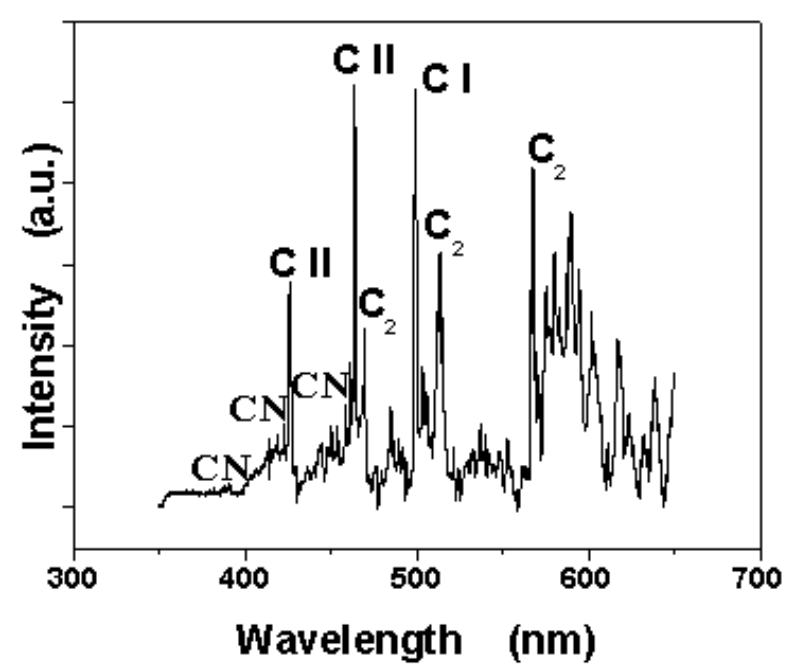

Figure 2. Typical optical emission spectrum of the plume of graphite ablation in nitrogen atmosphere at 30 mTorr and $3.03 \mathrm{x}$ $10^{9}$ Watts $/ \mathrm{cm}^{2}$.

The expanded spectra near the violet band emission of the $\mathrm{CN}$ molecule $\left(\mathrm{B}^{2} \Sigma^{+}-\mathrm{X}^{2} \Sigma^{+}\right)$and the $\mathrm{C}_{2}$ Swam band emission $\left(\mathrm{A}^{3} \Pi_{g}-\mathrm{X}^{3} \Pi_{u}\right)$, are shown in Figs. 3a and $3 \mathrm{~b}$. As illustrated in these figures, the $\mathrm{CN} \Delta \nu=0$ sequence is degraded to the UV with its $(0,0),(1,1),(2,2),(3,3)$, and $(4,4)$ vibrational transitions; while the $382-390 \mathrm{~nm}$ range and the bands of the $\mathrm{C}_{2}$ Swan system $\Delta \nu=+1$ is degraded to the red with its $(1,0),(2,1),(3,2),(5,4)$, and $(6,5)$, dominating the spectral region from 460 to $480 \mathrm{~nm}$. The observed emission lines are identified using the information consigned in Ref. 3 . The variation of the emission intensities of $391.1(11,11)$, $388.34(0,0)$, and $387.14(1,1) \mathrm{nm}$ lines associated to the $\mathrm{CN}$ Violet system, and $467.8(5,4), 471.5(2,1) \mathrm{nm}$ lines from the Swan system, and $\mathrm{C}^{++*} 464.7 \mathrm{~nm}$ line, are observed, in Figs. $4 \mathrm{a}$ and $4 \mathrm{~b}$, for nitrogen pressure up to 5 mTorr at $\sim 10$ $\mathrm{J} / \mathrm{cm}^{2}$. The emission intensities of all $\mathrm{CN}, \mathrm{C}_{2}$, and $\mathrm{C}^{++*}$ increase with increased nitrogen pressure. Furthermore, the intensities of $\mathrm{C}_{2}$ lines are stronger than $\mathrm{CN}$ molecules, indicating that plume thermalization, caused by collisions of $\mathrm{C}$ species with background nitrogen molecules promote a larger recombination of $\mathrm{C}$ to form $\mathrm{C}_{2}$. This result can be correlated to the N/C ratio of deposited $\mathrm{CNx}$ films, calculated using the ratio between the $\mathrm{N} 1 \mathrm{~s}$ and $\mathrm{C}$ 1s peaks obtained through X-ray Photoemission Spectroscopy (XPS). We found that nitrogen content decreased from $23 \%$ to $18 \%$, as pressure was increased from 5 to 30 mTorr [12].

In order to determine formation mechanisms, we have estimated the vibrational temperature of $\mathrm{CN}$ molecules using a relative emission intensity method. Assuming a Boltzmann distribution in the density of excited molecular levels, the emission intensity of vibrational transition $\left(\mathrm{I}_{\nu / \nu \prime \prime}\right)$ is related to the vibrational temperature $\left(\mathrm{T}_{v i b}\right)$ by expression [13]: 

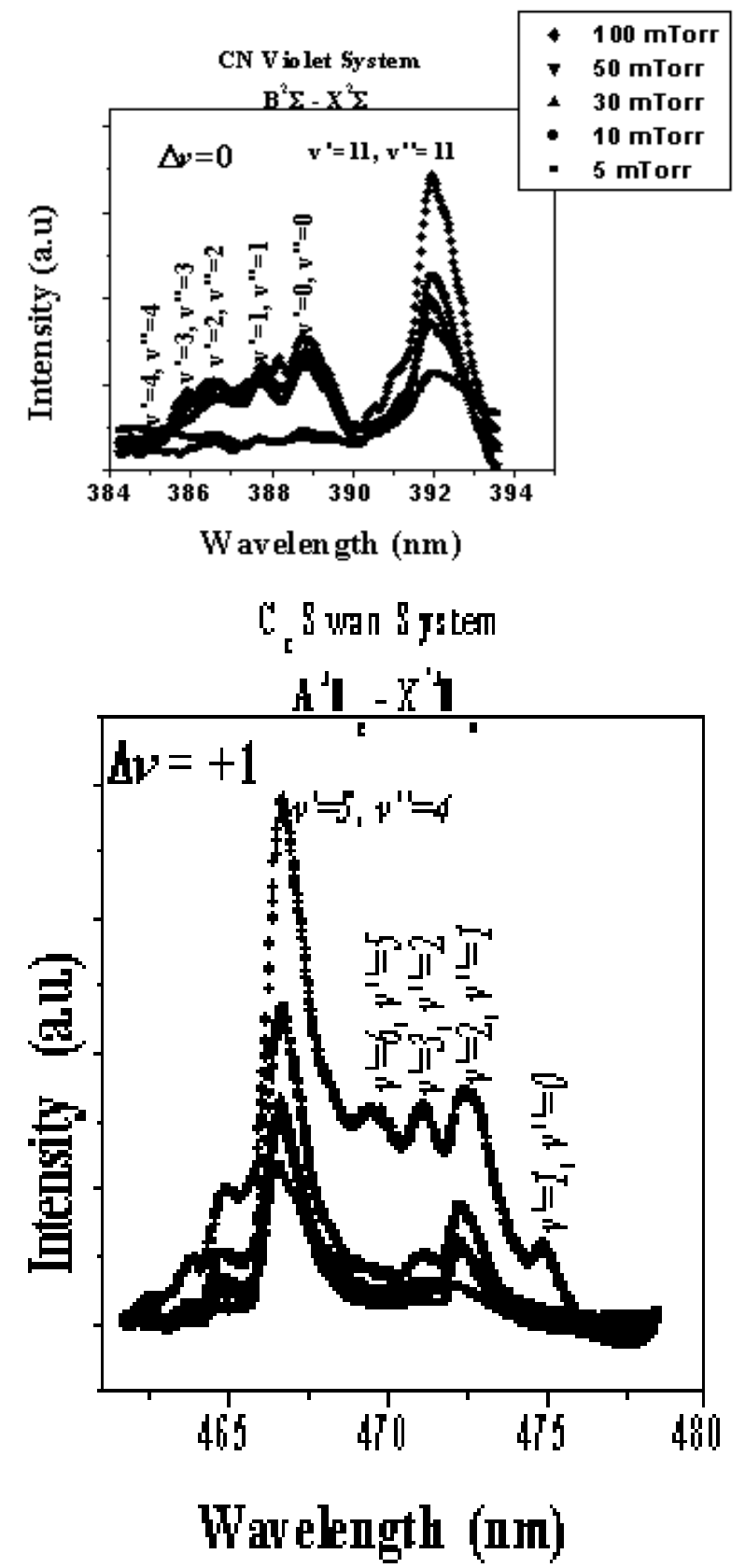

Figure 3. Spectra at different pressures of Nitrogen background: a) CN Violet system $B^{2} \Sigma^{+}-X^{2} \Sigma^{+}$with $\Delta \nu=0$; b) $C_{2}$ Swan system $A^{3} \Pi_{g}-X^{\prime 3} \Pi_{u}$ with $\Delta \nu=+1$.

$$
\ln \sum_{\nu^{\prime \prime}}\left(\lambda^{4} I_{\nu^{\prime} \nu^{\prime \prime}}\right)=C_{1}-G\left(\nu^{\prime}\right)\left[\frac{h c}{\kappa T_{v i b}}\right]
$$

where $\nu^{\prime}$ and $\nu^{\prime \prime}$ are the vibrational quantum number of upper and lower levels, respectively; $\lambda$ is the wavelength corresponding to the transition $\left(\nu^{\prime}, \nu^{\prime \prime}\right) ; \mathrm{G}\left(\nu^{\prime}\right)$ is the upper vibrational level; $\mathrm{C}_{1}$ is a constant; $\mathrm{h}$ is Planck's constant; $\kappa$ is Boltzmann's constant; and $\mathrm{c}$ is the speed of light. Vibrational energy levels and the emission wavelength of the diatomic CN (B $\left.{ }^{2} \Sigma^{+}-\mathrm{X}^{2} \Sigma^{+}\right)$molecule were calculated using molecular constants given in Ref. 14 .
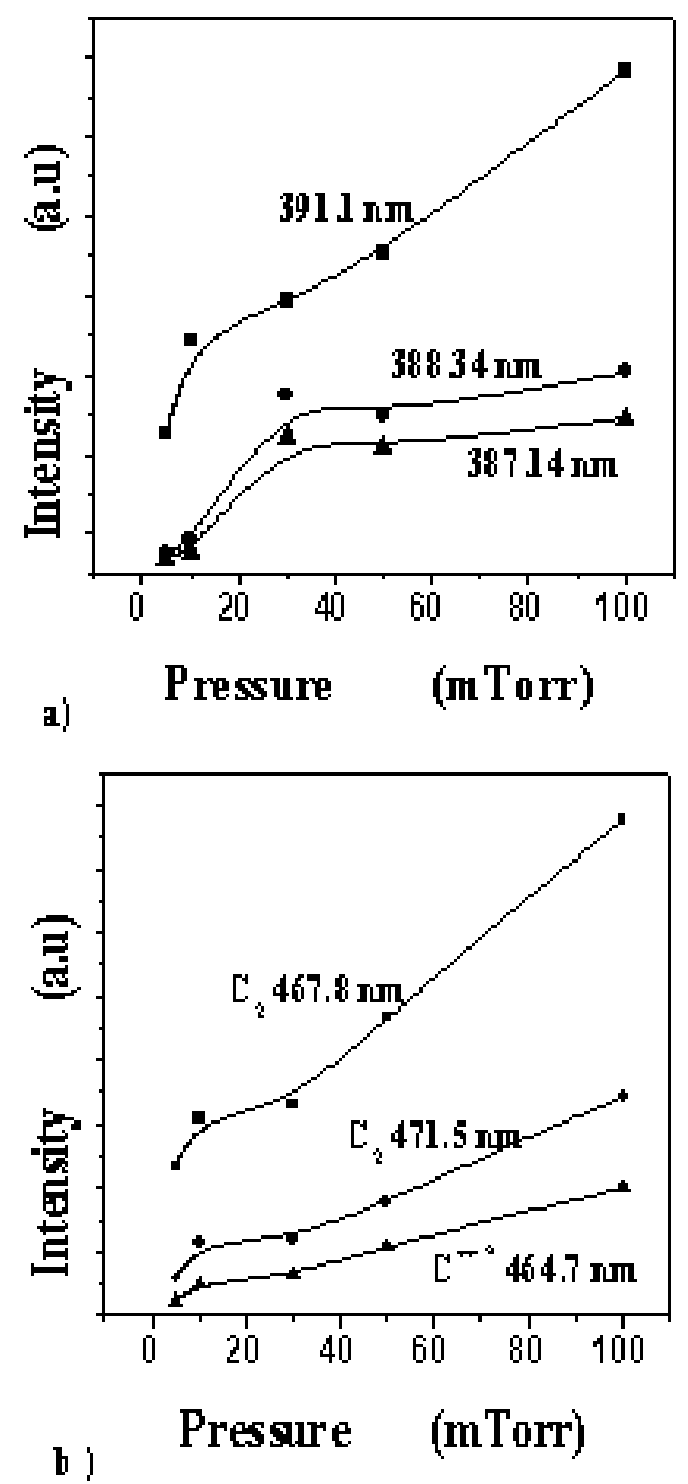

Figure 4. Emission intensities of: a) $391.1(11,11), 388.34(0,0)$ and $387.14(1,1) \mathrm{nm}$ lines associated to the $\mathrm{CN}$ Violet system; $\mathrm{b})$ $467.8(5,4), 471.5(2,1) \mathrm{nm}$ lines of Swan system and $\mathrm{C}^{++*} 464.7$ $\mathrm{nm}$ line from graphite plasma plume as a function of nitrogen pressure. Power density $12 \mathrm{~J} / \mathrm{cm}^{2}$. Lines are guide to the axis.

Figure 5a plots data for $\mathrm{CN}$ emission peaks at $388.3 \mathrm{~nm}$ $(0,0), 387.1 \mathrm{~nm}(1,1), 386.2 \mathrm{~nm}(2,2), 385.1 \mathrm{~nm}(4,4)$ according to equation (1), for different nitrogen pressures. Slopes are inversely proportional to $\mathrm{T}_{v i b}$, demonstrating a decrease in vibrational temperature from 2.64 to $1.23 \mathrm{eV}$, as pressure increased from 5 to 100 mTorr (see Fig. 5b). This behavior agrees with previously reported results $[1,3,15]$ for fullerene-like CNx films obtained by laser ablation of graphite in nitrogen using an excimer laser. At 5 mTorr, we observe strong increase of vibrational temperature, due to the occurrence of fewer plume collisions on the way to the substrate. Vibrational temperature at 5 mTorr $(2.64 \mathrm{eV})$ is sufficiently close to the bonding energies of $\mathrm{CN}$ molecules $(3.8 \mathrm{eV})$ to influence composition and film structure. In fact, films grown at $5 \mathrm{mTorr}$ presented the highest $\mathrm{N}$ content (23\%) and $\mathrm{P}_{2} / \mathrm{P}_{3}$ ratio (1.41), for $\mathrm{N} 1$ s nitrogen bonding and the highest Raman $\mathrm{I}(\mathrm{D}) / \mathrm{I}(\mathrm{G})$ ratio $(2.45)$, related to the 
lowest G-peak position $\left(1548.1 \mathrm{~cm}^{-1}\right)$. These results indicate highest fullerene likeness under our experimental conditions [12].
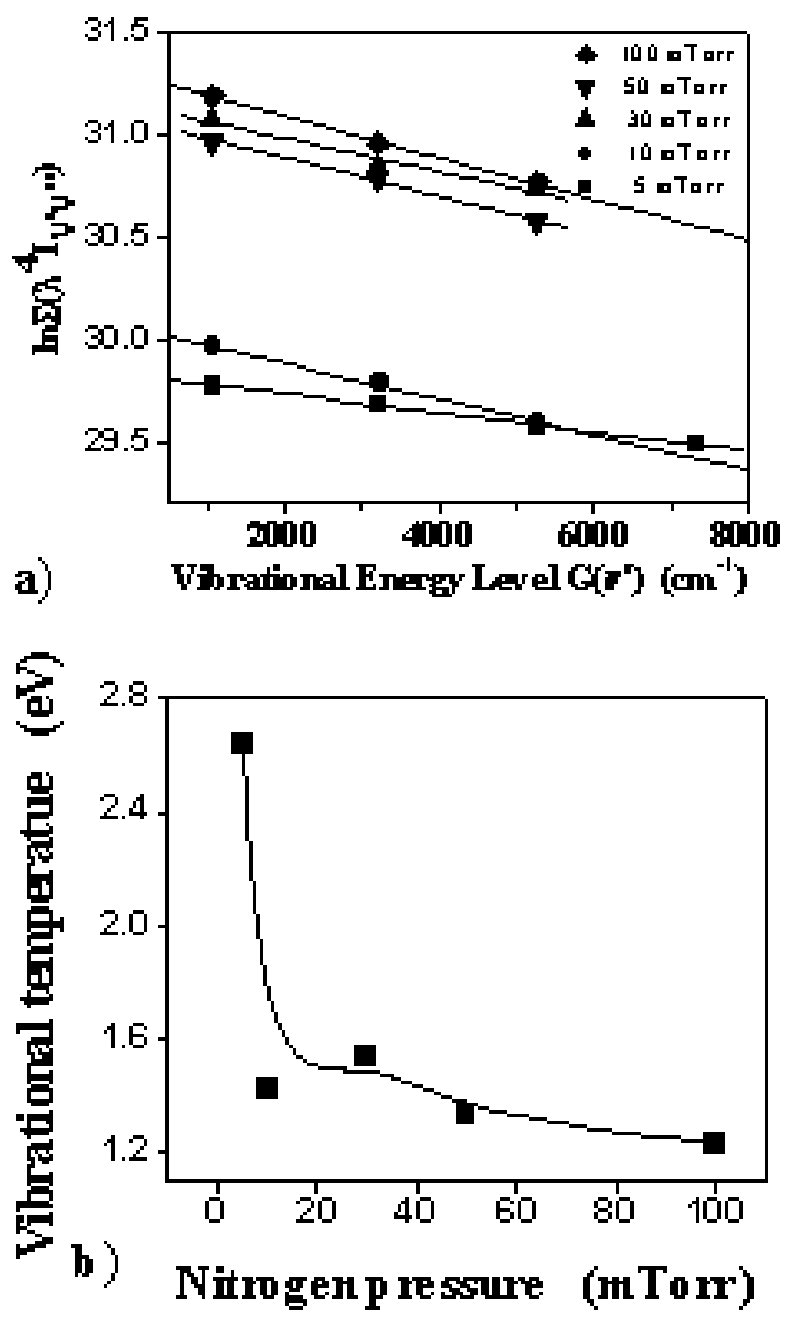

Figure 5. a) Boltzmann plots emission intensities of $\mathrm{CN}$ vibrational spectra for different nitrogen pressures. b) Vibrational temperature as a function of Nitrogen pressure. Lines are guide to the axis.

\section{Conclusions}

Plasma produced by laser ablation of graphite at low nitrogen pressures by using an Nd: YAG-pulsed laser, were analyzed for synthesis of fullerene-like CNx films. Plasma composition and vibrational temperature was correlated to film composition and bonding. We concluded that:

Close to the target, plasma is dominated by strong peaks of excited neutral, $\mathrm{C}(\mathrm{I})$, and single ionized, $\mathrm{C}(\mathrm{II})$, atoms, $\mathrm{CN}$ radicals, and $\mathrm{C}_{2}$ molecules, characteristic of carbon plasma in the presence of reactive nitrogen.

Detection of $\mathrm{C}_{2}$ and $\mathrm{CN}$ molecules is related to plume thermalization caused by collisions with background nitrogen molecules, promoting recombination of $\mathrm{C}$ to form $\mathrm{C}_{2}$ and provide a large fraction of $\mathrm{sp}^{2}$ hybridization, thus favoring fullerene-like $\mathrm{CNx}$ formations.
The intensities of $\mathrm{C}_{2}$ lines are stronger than the intensities of $\mathrm{CN}$ lines. This result was correlated with the nitrogen content in the deposited $\mathrm{CNx}$ films. We have found that nitrogen content decreases from $23 \%$ to $18 \%$, as pressure increases from 5 to 30 mTorr.

Vibrational temperature decreases from 2.64 to $1.23 \mathrm{eV}$, as pressure increases from 5 to 100 mTorr. Vibrational temperature at $5 \mathrm{mTorr}(2.64 \mathrm{eV})$ is sufficiently close to the bonding energies of $\mathrm{CN}$ molecule $(3.8 \mathrm{eV})$ to influence composition and film structure. These results agree with the composition and structure of deposited fullerene-like $\mathrm{CNx}$ films.

\section{Acknowledgment}

This work has been financed and supported by COLCIENCIAS, Colombia, under research project No. 1106-0511457 (contract 252-2001) and by FUNDACION BANCO DE LA REPUBLICA, Colombia, under research project No. 1441.

\section{References}

[1] Y. Yamagata, A. Sharma, J. Narayan, R. M. Mayo, J. W. Newman, and K. Ebihara, J. Appl. Phys. 86, 4154 (1999).

[2] Y. Yamagata, A. Sharma, J. Narayan, R. M. Mayo, J. W. Newman, and K. Ebihara, J. Appl. Phys. 88, 6861 (2000).

[3] A. A. Voevodin, J. G. Jones, J. S. Zabinski, and L. Hultman, J. Appl. Phys. 92, 9, 724 (2002).

[4] F. Acquaviva, M. L. De Giorgi, Appl. Surf. Science 197-198, 21-26 (2002)

[5] F. Kokai, Y. Koga, and R. B. Heimann, Appl. Surf. Sci. 96-98, 261 (1996).

[6] Y. Nakata, H. Kaibara, T. Okada, and M. Maeda, J. Appl. Phys. 80, 2558 (1996).

[7] Y. Yamagata, K. Shingai, A. M. Alexander, T. Ikegami, and K. Ebihara, Thin Solid Films 316, 56 (1998).

[8] A. A. Voevodin, S. J. P. Laube, S. D. Walck, J. S. Solomon, M. S. Donley, and J. S. Zabinsky, J. Appl. Phys. 78, 4123 (1995).

[9] Abhilasha, P. S. R. Prasad, and R. K. Thareja, Phys. Rev. A 48, 2929 (1993).

[10] R. W. B. Pearse and A. G. Gaydon, The Identification of Molecular Spectra (Chapman and Hall, New York, 1976).

[11] S. S. Harilal, R. C. Issac, C. V. Bindhu, V. P. N. Nampoori, and C. P. G. Vallabhan, J. Appl. Phys. 803561 (1996).

[12] H. Riascos, G. Zambrano, P. Prieto, A. Devia, H. Galindo, C. Power, and J. González (submitted to Physica Status Solidi).

[13] X. Chen, J. Mazumder, and A. Purohit, Appl. Phys. A: Solids Surf. 52, 328 (1991).

[14] G. Herzberg, Molecular Spectra and Molecular Structure: Spectra of Diatomic Molecules (Krieger, Malabar, FL, 1989).

[15] S. S. Harilal, R. C. Isaac, C. V. Bindhu, P. Gopinath, V. P. N. Nampoori, and C. P. G. Vallabhan, Spectrochim. Acta A 53, 1527 (1997). 